Superalloys 2012: $12^{\text {th }}$ International Symposium on Superalloys

\title{
LOW CYCLE FATIGUE BEHAVIOR OF A NEW WROUGHT Ni-Co-BASE DISK SUPERALLOY TMW-4M3
}

\author{
Z.H. Zhong ${ }^{1}$, Y.F.Gu' ${ }^{1}$, Y. Yuan ${ }^{2}$, T. Osada ${ }^{1, a}$, T. Yokokawa², H. Harada ${ }^{2}$ \\ ${ }^{1}$ High Temperature Materials Unit, National Institute for Materials Science (NIMS), 1-2-1 Sengen, Tsukuba, Ibaraki 305-0047, Japan \\ ${ }^{2}$ Environment and Energy Materials Division, NIMS, 1-2-1 Sengen, Tsukuba, Ibaraki 305-0047, Japan \\ ${ }^{\mathrm{a}}$ Present address: Yokohama National University, Yokohama 240-8501, Japan
}

Keywords: Disk alloy, TMW-4M3, Low cycle fatigue, Cyclic stress response, Crack initiation

\begin{abstract}
The low cycle fatigue behavior of a new cast and wrought $\mathrm{Ni}-\mathrm{Co}-$ base superalloy TMW-4M3 was studied at 400,650 and $725{ }^{\circ} \mathrm{C}$ under various strain ranges (0.79-1.22\%). Detailed studies were performed on cyclic hardening/softening behavior, deformation substructure, fatigue life, as well as crack initiation and subsequent propagation. Continuous cyclic hardening until fracture was observed under various imposed strain ranges at 400 ${ }^{\circ} \mathrm{C}$. Such hardening behavior was absent, whereas cyclic softening from the first cycle to failure at 650 and $725{ }^{\circ} \mathrm{C}$ was observed, except at $650{ }^{\circ} \mathrm{C}$ and low strain range $(0.8 \%)$ where specimen exhibited relative stable stress response until failure initiation. Transmission electron microscopy analysis reveals that the cyclic hardening is due to the inhomogeneous dislocation activity and interactions of dislocations, and that cyclic softening is related to shearing of precipitates by stacking fault and coupled dislocation pairs combining with thermal activation process. Fatigue life decreased with increasing the test temperature or strain range. The relation between fatigue life and plastic strain followed the Coffin-Manson relation. Cracks often initiated on or near the surfaces of specimen during cycling, while subsurface carbide clusters initiation was also observed. Oxidation plays key role in accelerating crack propagation at 650 and $725^{\circ} \mathrm{C}$.
\end{abstract}

\section{Introduction}

Many polycrystalline Ni-base superalloys have been developed for wide use in critical components, e.g. disk, of turbine engines because of their excellent mechanical properties and environmental resistance at elevated temperatures. The operating temperatures of high-pressure turbine disks and commercial pressures have continued to challenge materials and design engineers as temperatures now approach $700{ }^{\circ} \mathrm{C}$ and even higher for military applications and ever-growing cost reduction requirement. Generally, commercially available cast and wrought (C\&W) superalloys such as U720Li for turbine disks applications are confined to be used below $680{ }^{\circ} \mathrm{C}$ due to the degradation of their mechanical properties [1]. Hence, a disk superalloy with required balance mechanical properties that could be operated above $700{ }^{\circ} \mathrm{C}$ is highly desired. Ni-Co-base superalloys [2-5], named TMW alloys, recently developed by the National Institute for Materials Science of Japan, are promising ones. TMW-4M3, one of the TMW alloys, showed a possibility of $76{ }^{\circ} \mathrm{C}$ higher working temperature than U720Li [2].

The main role of turbine disk is to hold the turbine blade with high rotational speeds/temperatures and to transmit the power to the high pressure turbine shaft. Thus, the disk is subjected to repeated thermal and mechanical stresses during start-up, steadystate, and shut-down operations. Although precipitation strengthened superalloys keep excellent monotonic strength levels up to high fractions of their melting point $\left(\sim 0.6 T_{m}\right)$, the lives of superalloys are often shortened during service due to fatigue, especially when the cyclic loading is applied at low frequency and in an oxidizing environment [6,7]. Therefore, the resistance to fatigue at elevated temperatures is an essential property for disk alloy and must be evaluated for candidate alloys. The objective of this paper was to investigate the low cycle fatigue (LCF) behavior of newly developed TMW-4M3 and to relate this to the substructure with respect to dislocation configurations.

\section{Materials and Experimental Procedures}

The chemical composition of TMW-4M3 is listed in Table I. The microstructure of the alloy consists primarily of $\gamma$ matrix and $\gamma^{\prime}$ precipitates, as shown in Fig. 1. The un-dissolved primary $\gamma^{\prime}$ precipitates with a size of $0.5-2.5 \mu \mathrm{m}$ are distributed between $\gamma$ grains or in the interior of grains (Fig. 1(a)). The volume fraction of primary $\gamma^{\prime}$ was about $16.9 \%$. Aging twins were also discernible within some grains. In addition, small quantities of $\mathrm{M}_{23} \mathrm{C}_{6}$ or $\mathrm{MC}$ carbides $(\sim 0.5 \%)$ were also present at grain boundaries. Fine secondary (30-100 nm in diameter) and tertiary $\gamma(5-10 \mathrm{~nm})$ particles precipitated in $\gamma$ grain can be seen in Fig. 1(b).
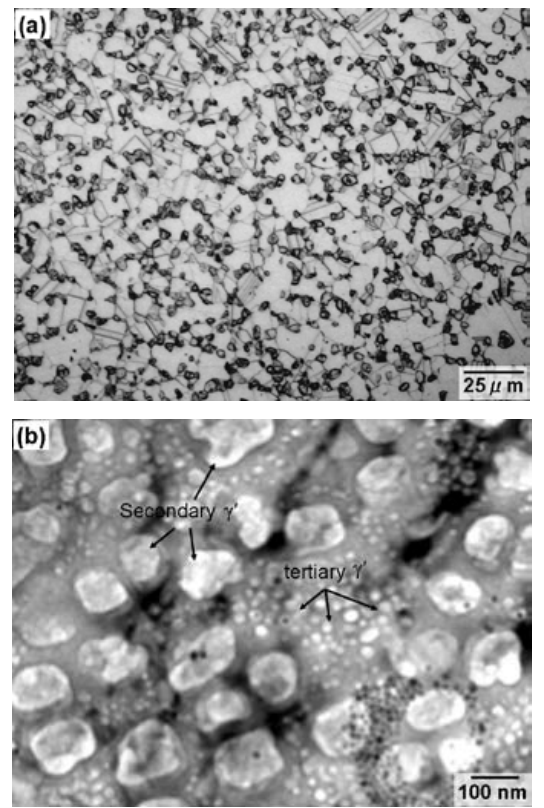

Figure 1. (a) Optical micrograph and (b) transmission electron micrograph (bright field image) showing the grain structure and distribution of $\gamma^{\prime}$ precipitates of TMW-4M3. 
Table I. Nominal Chemical Compositions (wt.\%) of TMW-4M3.

\begin{tabular}{ccccccccccc}
\hline Alloy & $\mathrm{Ni}$ & $\mathrm{Co}$ & $\mathrm{Cr}$ & $\mathrm{Mo}$ & $\mathrm{W}$ & $\mathrm{Al}$ & $\mathrm{Ti}$ & $\mathrm{C}$ & $\mathrm{B}$ & $\mathrm{Zr}$ \\
\hline TMW-4M3 & Bal. & 25.0 & 13.5 & 2.8 & 1.2 & 2.3 & 6.2 & 0.02 & 0.02 & 0.03 \\
\hline
\end{tabular}

All LCF tests were carried out on a threaded round specimen with $6.35 \mathrm{~mm}$ in gauge diameter and $12 \mathrm{~mm}$ in gauge length. Prior to testing, specimens were polished with 600\# sand paper parallel to the stress axis to remove any circumferential/radial scratches/machining marks that might act as crack initiation sites. The LCF tests were carried out in a computer-controlled MTS New 810 servo-hydraulic machine. Tests were conducted in air at 400 , 650, and $725{ }^{\circ} \mathrm{C}$ under longitudinal strain-controlled conditions with total strain range $\left(\Delta \varepsilon_{\mathrm{t}}\right)$ varied from 0.79 to $1.22 \%$. The strain ratio $\left(R_{\varepsilon}\right)$ of minimum to maximum strain was zero. An identical frequency of $0.5 \mathrm{~Hz}$, applied in symmetric triangular waveform was used for each test. All the tests were started after the temperature reached the designated values for $10 \mathrm{~min}$, and the temperature over the gauge length was maintained within $\pm 5{ }^{\circ} \mathrm{C}$. The fatigue tests were continued until fracture occurred in the specimens.

The fracture surfaces of fatigued samples were examined by scanning electron microscopy (SEM) to determine the crack initiation and propagation modes. Deformation-induced substructures were studied by transmission electron microscopy (TEM). Samples for TEM examination were obtained from thin foils sliced from adjacent to the fracture surface. Discs of $3 \mathrm{~mm}$ in diameter were punched out from the foils after which were mechanically thinned down to about $50 \mu \mathrm{m}$, and followed by twin-jet electrolytic thinning in a chemical solution $(10 \mathrm{vol} \%$ perchloric acid, 20 vol\% ethanol, and 60 vol\% n-butoxyethanol) at about $0{ }^{\circ} \mathrm{C}$ and $20 \mathrm{~mA}$. TEM observation was performed on TECNAI-20* operated at $200 \mathrm{kV}$.

\section{Results and Discussion}

\section{Evolution of cyclic stress}

The cyclic tensile stress responses at various strain levels for different test temperatures are shown in Fig.2. It can be seen that, the cyclic stress response of TMW-4M3 is closely related with both strain range and test temperature. At $400{ }^{\circ} \mathrm{C}$, continuous increase of the peak tensile stress (hardening) was observed prior to the onset of the microcrack initiation stage at all the strain ranges. At 650 and $725{ }^{\circ} \mathrm{C}$, however, the evolution of the stress with the number of cycles was found to be different from that observed at $400{ }^{\circ} \mathrm{C}$. Under all the strain ranges, the period of hardening was absent (Fig.2 (b) and (c)) and the specimens soften from the first cycle, except the specimen tested at $650{ }^{\circ} \mathrm{C}$ and $\Delta \varepsilon_{\mathrm{t}}=0.8 \%$, which shows relatively stable stress response with data fluctuation until failure initiation.

Cyclic behavior of specimens tested at various temperatures under a given strain range was compared in Fig. 3 . In this figure the normalized peak tensile stress corresponding to $\Delta \varepsilon_{\mathrm{t}}=1.0 \%$ has been plotted as a function of number of cycles at various temperatures. Again, these curves reveal that TMW-4M3 exhibited hardening behavior at $400{ }^{\circ} \mathrm{C}$ and softening at $650{ }^{\circ} \mathrm{C}$ and $725^{\circ} \mathrm{C}$.
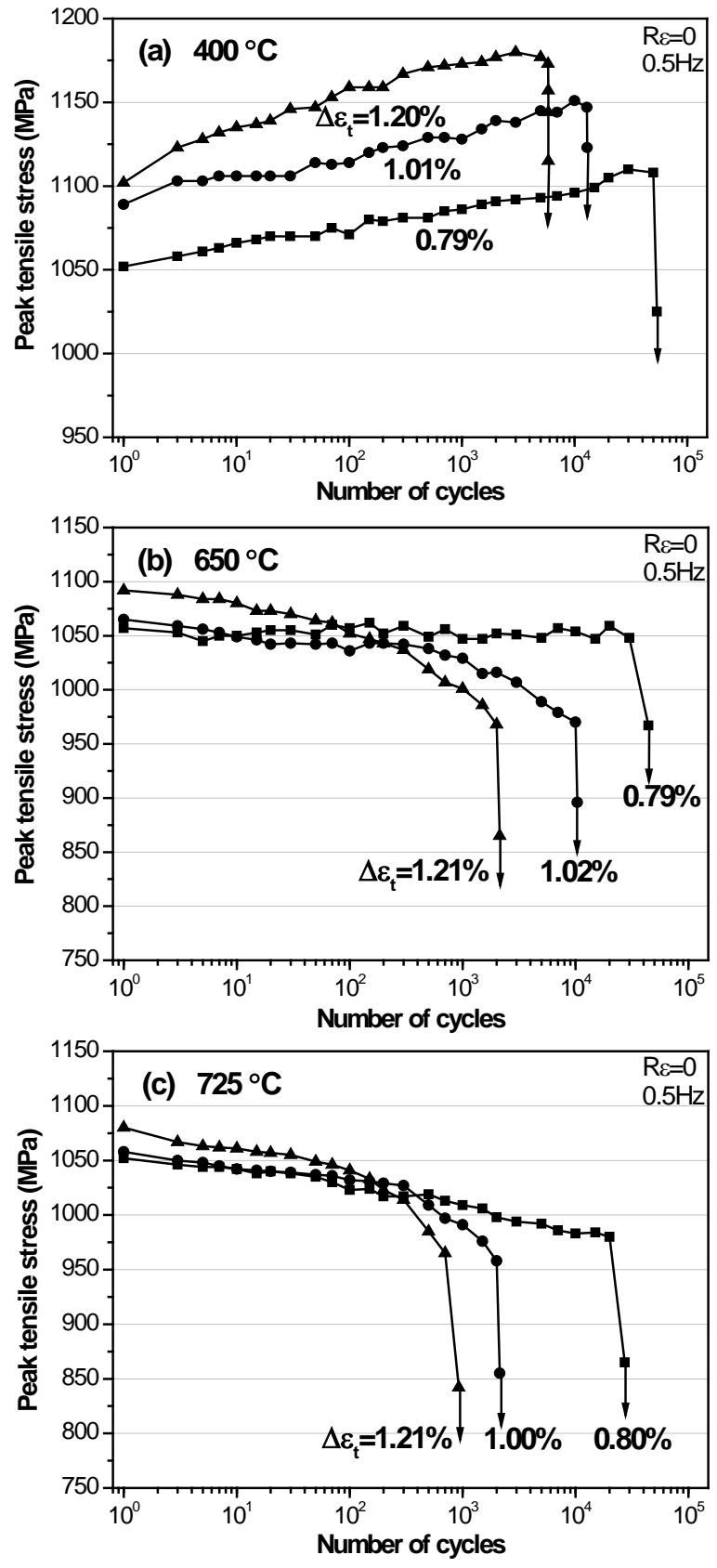

Figure 2. Evolution of the cyclic peak tensile stress with the number of cycles at (a) $400{ }^{\circ} \mathrm{C}$, (b) $650{ }^{\circ} \mathrm{C}$, and (c) $725{ }^{\circ} \mathrm{C}$. The cyclic hardening and softening depended on both temperature and strain range. 


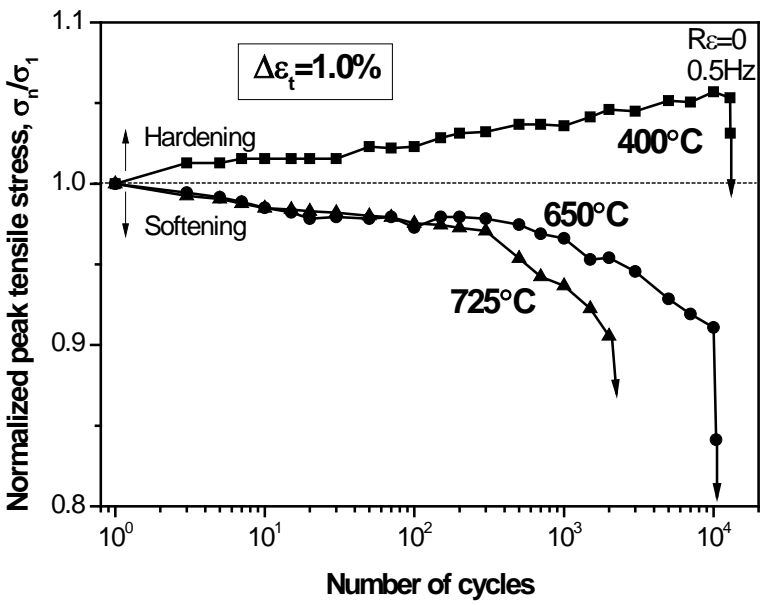

Figure 3. Comparison of the cyclic stress response at various temperatures for a strain range of $1.0 \%$.

\section{Degree of cyclic hardening/softening}

To quantify the degree of cyclic hardening/softening, the parameter 'hardening $D^{\prime}$ ' is calculated using the following equation [8]:

$$
D(\%)=\left[\frac{\sigma_{\text {mid-life }}-\sigma_{1}}{\sigma_{1}}\right] \times 100
$$

where $\sigma_{\text {mid-life }}$ is the peak tensile stress exhibited at mid-life, and $\sigma_{1}$ is the peak tensile stress at the first cycle. The variation of $D$ with temperature at each $\Delta \varepsilon_{\mathrm{t}}$ is shown in Fig. 4 . It is evident that, at 400 ${ }^{\circ} \mathrm{C}$, the magnitude of hardening of TMW-4M3 increased with increasing the $\Delta \varepsilon_{\mathrm{t}}$. At $650{ }^{\circ} \mathrm{C}$ and $725^{\circ} \mathrm{C}$, the negative values of $D$ were obtained, which indicated that the alloy soften during tests. At a given strain range, the degree of softening increased with increasing the temperature.

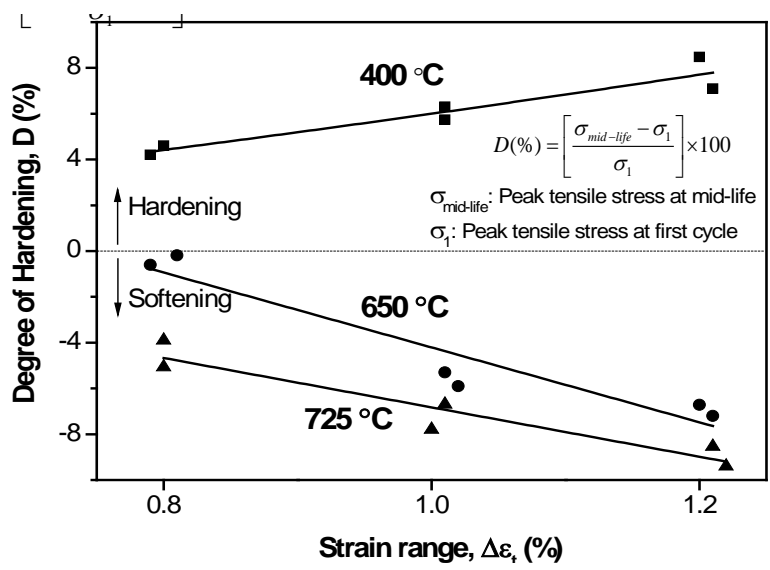

Figure 4. Degree of hardening $D$ calculated from cyclic stress response data.

\section{Low cycle fatigue life}

The number of loading cycles $\left(N_{f}\right)$ to specimen failure as a function of $\Delta \varepsilon_{\mathrm{t}}$ at different temperatures studied, is shown in Fig. 5. It can be seen that the fatigue lives of TMW-4M3 alloy exhibit dependence on the temperature and imposed strain range. The fatigue lives at $725{ }^{\circ} \mathrm{C}$ are clearly lower than those at 400 and 650 ${ }^{\circ} \mathrm{C}$ at all strain ranges. At a given $\Delta \varepsilon_{\mathrm{t}}$, the fatigue lives decreased with increasing test temperature. At a high $\Delta \varepsilon_{\mathrm{t}}$ of $1.2 \%$, the difference in fatigue lives at 650 and $725{ }^{\circ} \mathrm{C}$ is small. Since plastic strain and fatigue damage introduced in the specimen increase with increasing the imposed strain range at a given temperature, the observed higher lives at $400{ }^{\circ} \mathrm{C}$ than $650{ }^{\circ} \mathrm{C}$ or $725^{\circ} \mathrm{C}$ can be rationalized if lives are assessed as a function of plastic strain range $\left(\Delta \varepsilon_{\mathrm{p}}\right)$. In addition, as mentioned below, the crack propagation mode changes from transgranular to intergranular when the temperature increases from $400{ }^{\circ} \mathrm{C}$ to $725^{\circ} \mathrm{C}$, indicating the faster crack propagation rate at higher temperature after crack initiation. This is also responsible for the lower fatigue life at higher temperature.

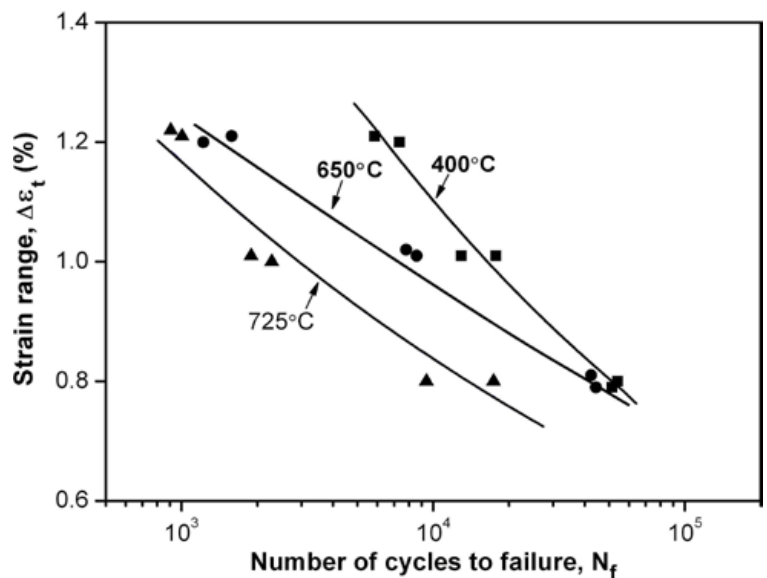

Figure 5. Dependence of fatigue life $\left(N_{f}\right)$ on imposed strain range $\left(\Delta \varepsilon_{t}\right)$ of TMW-4M3.

In view of the dominating influence $\Delta \varepsilon_{\mathrm{p}}$ on fatigue damage, the strain-controlled low cycle fatigue behavior could be described by the Coffin-Manson relationship [9-11] below:

$$
\Delta \varepsilon_{p}\left(N_{f}\right)^{\alpha}=C
$$

where $\alpha$ is the fatigue ductility exponent and $C$ is the fatigue ductility coefficient. Fig. 6 shows the relationship between $\Delta \varepsilon_{\mathrm{p}}$ and $N_{f}$. The data of $\Delta \varepsilon_{\mathrm{p}}$ were obtained from the stress-strain hysteresis loop at mid-life. With bilogarithmic coordinates a linear relationship is found between $\Delta \varepsilon_{\mathrm{p}}$ and $N_{f}$. Values of $\alpha$ and $C$ are tabulated in Table II. These values are very close to those generally measured in many alloys [12-14].

Table II. Fatigue Ductility Coefficient and Fatigue Ductility Exponent of TMW-4M3

\begin{tabular}{ccc}
\hline Temperature $\left({ }^{\circ} \mathrm{C}\right)$ & $C$ & $\alpha$ \\
\hline 400 & 75.713 & 1.720 \\
\hline 650 & 0.298 & 0.724 \\
\hline 725 & 0.115 & 0.675 \\
\hline
\end{tabular}




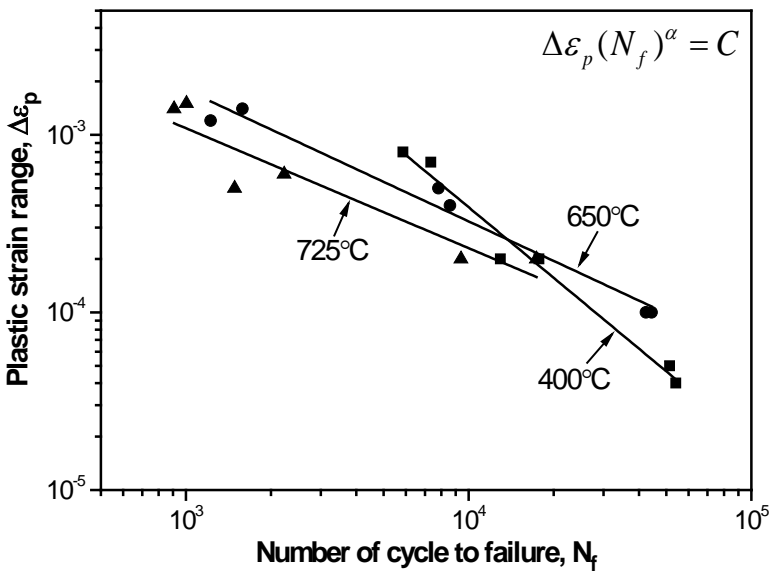

Figure 6. Dependence of the number of cycle to failure on plastic strain range $\Delta \varepsilon_{\mathrm{p}}$ at different temperatures.

\section{Deformation substructure and deformation mechanisms}

In order to characterize the development of the dislocation distribution after fatigue, specimens were microstructurally examined by TEM. The dislocation structure within the grains after cyclic deformation was strongly dependent both on temperature and strain range. In specimens subjected to $\Delta \varepsilon_{\mathrm{t}}=0.8 \%$ at $400{ }^{\circ} \mathrm{C}$, inhomogeneous dislocations was observed in the interior of grains. Isolated slip bands with low dislocation density and faults in $\gamma^{\prime}$ precipitates could be observed (Fig. 7(a)). These dislocations are of edge type, indicating planar slip behavior along the primary slip system. At $\Delta \varepsilon_{\mathrm{t}}=1.2 \%$, intense slip bands and a high dislocation density within the bands were seen, Fig. 7(b). It seems that dislocations displayed a preferential tendency to arrange themselves in planar arrays due to the low SFE of TMW4M3 [15]. Cyclic deformation occurred by simultaneous operation of two independent $\{110\}$ slip systems, and the interactions between dislocations at intersecting points gave rise to localized networks that impeding dislocation movement. Such behaviors are considered to be the causes for the observed cyclic hardening. In addition, inhomogeneous distribution of dislocations in the grains and around the primary $\gamma^{\prime}$ precipitates was also observed, as shown in Fig. 7(c). This suggests that the primary $\gamma^{\prime}$ precipitates act as obstacles hindering the motion of dislocations. In order to maintain the strain rate, the response stress has to increase enough to generate additional mobile dislocations or to penetrate the $\gamma^{\prime}$ precipitates, resulting in cyclic hardening.

As observed at $400{ }^{\circ} \mathrm{C}$, deformation by planar slip of dislocations was still predominant at $650{ }^{\circ} \mathrm{C}$, and stacking faults fringes on $\gamma^{\prime}$ precipitates were readily seen. No slip bands were observed and plastic deformation became more uniform. At $\Delta \varepsilon_{\mathrm{t}}=0.8 \%$, while some dislocations pairs and loops around the $\gamma^{\prime}$ precipitates were visible in some grains, the dominant deformation mode is $\gamma^{\prime}$ precipitates faulting by stacking faults, as shown in Fig. 8(a) and (b). At higher $\Delta \varepsilon_{\mathrm{t}}$ of $1.2 \%$, besides the stacking faults, dislocation loops could be seen, Fig. 8(c) and (d). This indicates that the deformation modes are $\gamma^{\prime}$ shearing and dislocation bowing between the precipitates. Therefore, the cyclic softening observed is thought to be due, in part at least, to shearing of $\gamma^{\prime}$ precipitates. Shearing of $\gamma^{\prime}$ precipitates have been considered for the causes of softening behavior in precipitation strengthened Ni-base superalloys [16-20]. Repeated shearing of $\gamma^{\prime}$ precipitates in successive cycles leads to a reduction in their size, and consequently the stress necessary to shear the precipitates for the subsequent cycles is reduced. On the other hand, the presence of dislocation loops around $\gamma^{\prime}$ precipitates shown in Fig. 8 (d) indicates that local climb events allow nearby dislocation line lengths to relax, partly annihilate, and form remnant loops. As temperature increased from 400 to $650{ }^{\circ} \mathrm{C}$, more slip systems and non-planar slip (climb) of dislocations are operative, further contributes to cycling softening.
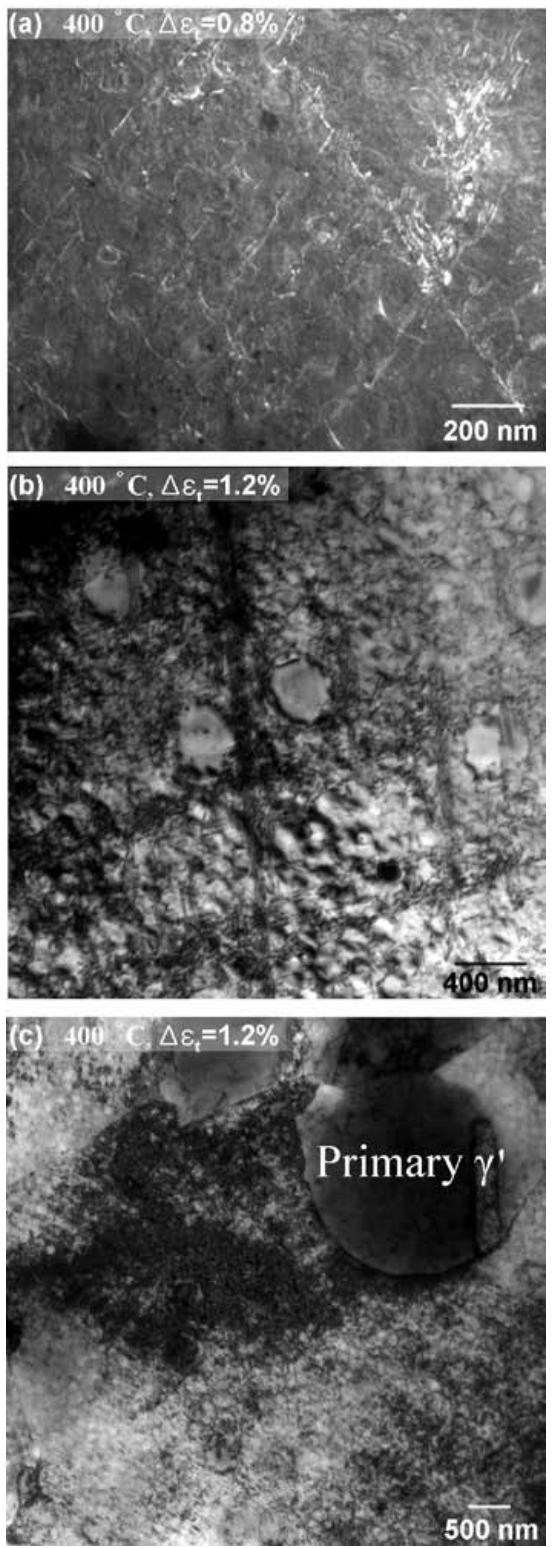

Figure 7. TEM micrographs of deformation substructure in TMW4M3 fatigued at $400{ }^{\circ} \mathrm{C}$. (a) $\Delta \varepsilon_{\mathrm{t}}=0.8 \%$, planar slip and relatively low dislocation density are observed; (b) and (c) $\Delta \varepsilon_{\mathrm{t}}=1.2 \%$, deformation bands on two slip planes, high dislocation density, and inhomogeneous dislocation activity around primary $\gamma^{\prime}$ are observed. 

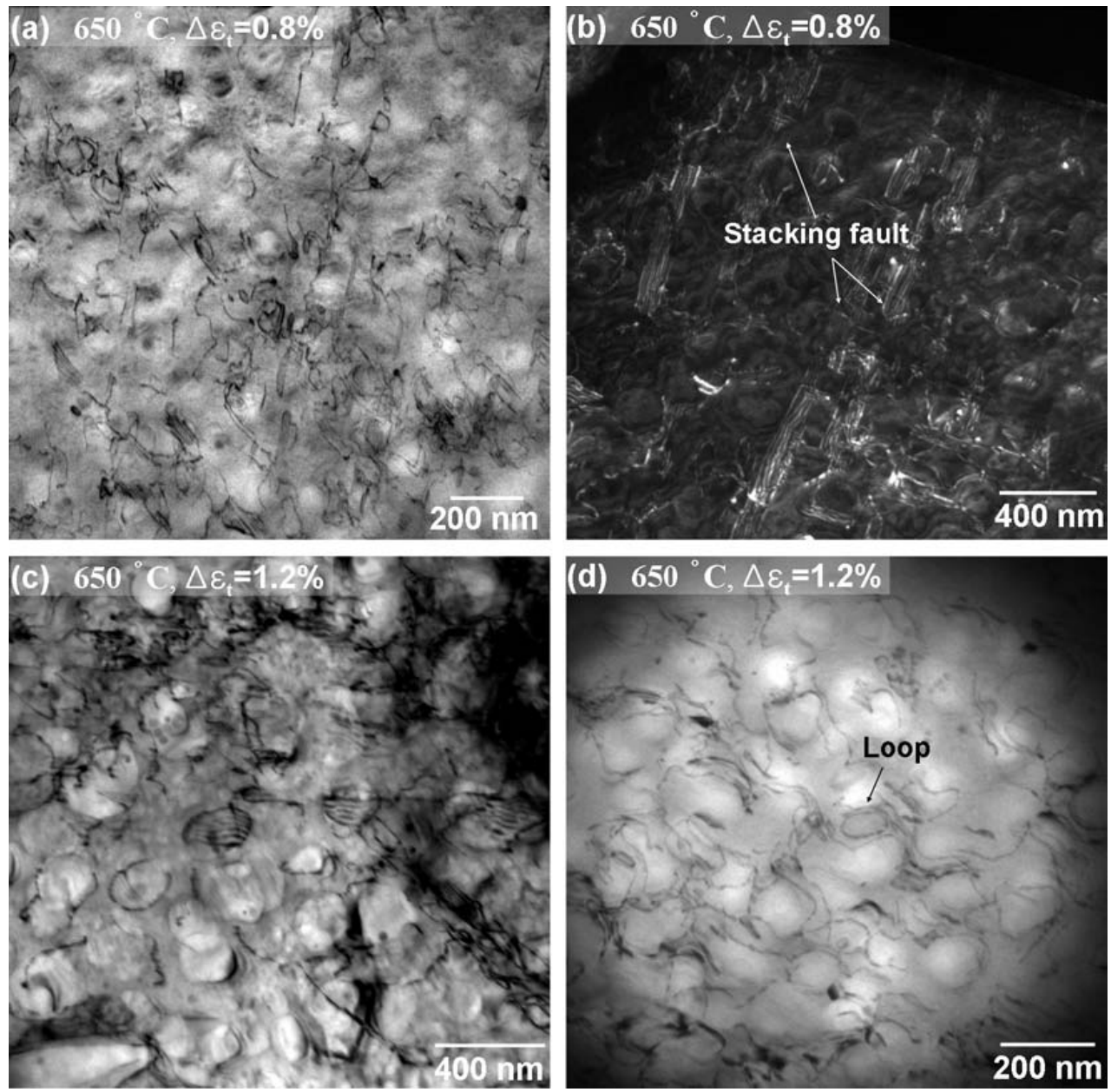

Figure 8. The deformation microstructure of TMW-4M3 fatigued at $650{ }^{\circ} \mathrm{C}$. (a) and (b) $\Delta \varepsilon_{\mathrm{t}}=0.8 \%$, partial dislocations shearing secondary $\gamma$, leaving stacking faults behind; (c) and (d) $\Delta \varepsilon_{\mathrm{t}}=1.2 \%$, stacking faults on secondary $\gamma^{\prime}$, dislocation loop and homogeneous dislocation activity are observed.
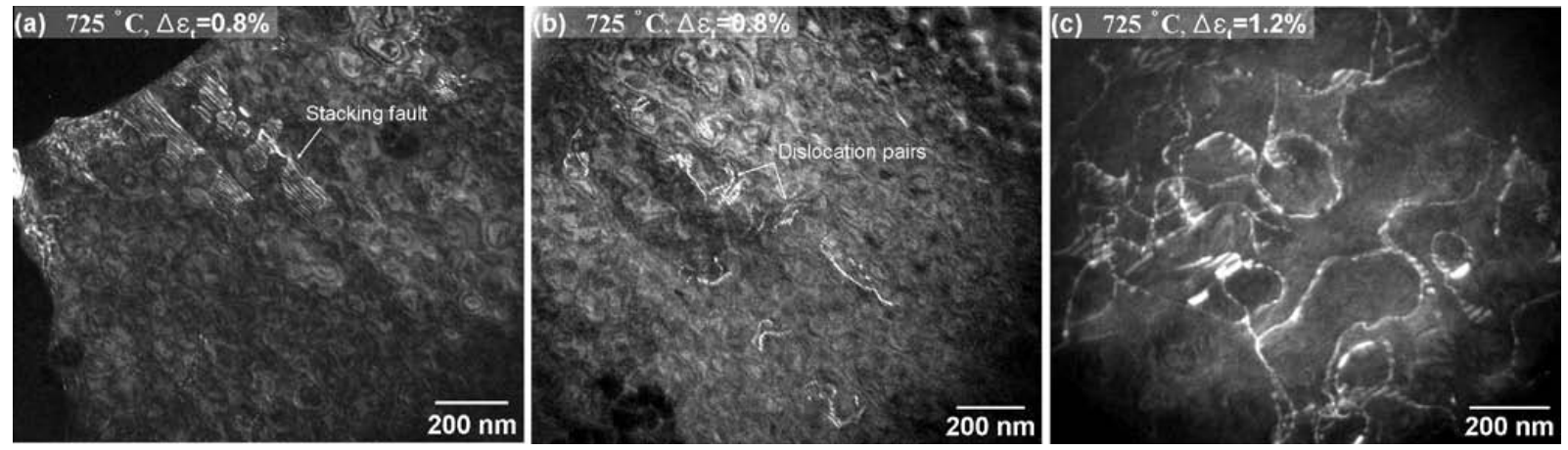

Figure 9. The deformation microstructure of TMW-4M3 fatigued at $725{ }^{\circ} \mathrm{C}$. (a) and (b) $\Delta \varepsilon_{\mathrm{t}}=0.8 \%$, stacking faults and dislocation pairs were observed, indicative of shearing of secondary $\gamma$; (c) $\Delta \varepsilon_{\mathrm{t}}=1.2 \%$, dislocation bowing and dislocation loops around the precipitates at $725{ }^{\circ} \mathrm{C}$ are observed. Low dislocation density is shown. 
In the tests at $750{ }^{\circ} \mathrm{C}$, as shown in Fig.9, while precipitates shearing by stacking faults was occasionally observed (Fig.9(a)), the dislocation pairs, which is indicative of precipitate shearing, are easily to be seen at $\Delta \varepsilon_{\mathrm{t}}=0.8 \%$ (Fig.9(b)). What is more, the density of dislocation decreased significantly compared to that at 400 and $650{ }^{\circ} \mathrm{C}$. Therefore, besides the shearing of $\gamma^{\prime}$ precipitates, the recovery processes such as dislocation annihilation and/or rearrangement, which lead to the formation of a configuration offering less resistance to dislocation movement, also contributed to the cyclic softening at $725{ }^{\circ} \mathrm{C}$. Cyclic softening caused by dislocation annihilation and/or rearrangement were also extensively observed in many superalloys [21-23] and steel [24] at elevated temperatures. At $\Delta \varepsilon_{\mathrm{t}}=1.2 \%$, deformation occurs primarily by dislocations bowing around the particles with few dislocation pairs. Thus the nature of the deformation is Orowan looping combined with slip and climb of dislocations.

\section{Fatigue crack initiation and propagation}

Scanning electron microscopy was used in failure analysis of fracture surfaces of LCF tested specimens. At $400{ }^{\circ} \mathrm{C}$ and $\Delta \varepsilon_{\mathrm{t}}=0.8 \%$, crystallographic initiation at large grains near to the surface of specimen was observed (Fig.10(a)). As $\Delta \varepsilon_{\mathrm{t}}$ increased to $1.0 \%$ and $1.2 \%$, fatigue crack initiated on the specimen surface (Fig.10(b)) At $650{ }^{\circ} \mathrm{C}$ and $\Delta \varepsilon_{\mathrm{t}}=0.8 \%$, crack initiated at the subsurface of the specimen (about $0.8 \mathrm{~mm}$ distant from the surface), as shown in Fig.10(c). Energy-dispersive spectroscopy (EDS) analysis on the particle cluster revealed that the particles were most likely carbides which formed during alloy processing. At $\Delta \varepsilon_{\mathrm{t}}=1.2$ and $1.0 \%$, cracks initiated on the specimen surface (Fig.10(d)) which is similar to these observed at $400{ }^{\circ} \mathrm{C}$. At 725 ${ }^{\circ} \mathrm{C}$, similarly, the cracks initiated near to the specimen surface under lower strain range $(0.8 \%)$ (Fig.10(e)) or on the surface under higher strain ranges (1.0 and 1.2\%) test (Fig.10(f)).
The fatigue crack propagation characteristics near the initiation sites were also determined. At $400{ }^{\circ} \mathrm{C}$, fatigue striations were observed on the fracture surface (Fig.11(a) and (b)), which are taken as evidences of transgranular mode. Transgranular crack propagation was found at $650{ }^{\circ} \mathrm{C}$ and $\Delta \varepsilon_{\mathrm{t}}=0.8 \%$ (Fig.11(c)). However, at $650{ }^{\circ} \mathrm{C}$ and $\Delta \varepsilon_{\mathrm{t}}=1.2 \%$, mixed transgranular and intergranular fractures and secondary cracks on the fracture surface were observed (Fig.11(d)). In addition, oxide scale on the fracture surfaces was also found, indicating the severe oxidation occurred during LCF tests at high temperature, and this may accelerate the crack propagation and consequently reduce the fatigue life of alloy. At $725{ }^{\circ} \mathrm{C}$ and $\Delta \varepsilon_{\mathrm{t}}=0.8 \%$, mixed transgranular and intergranular cracking was observed (Fig.11(e)), while predominant intergranular cracking on the fracture surface was observed at $\Delta \varepsilon_{\mathrm{t}}=1.2 \%$ (Fig.11(f)).

The LCF life includes two successive stages, the initiation and the subsequent propagation of fatigue cracks. It has been reported [13] that, at elevated temperatures, the fatigue life depends largely on the process of crack initiation and propagation to a small crack of $50-100 \mu \mathrm{m}$. In the present study, two crack initiation modes were observed from the fracture surfaces, depending on the total strain range and temperature. These were cracks nucleating due to plastic damage accumulation within slip bands on or near the specimen surface and cracks initiating at subsurface carbide clusters. Surface or near surface crack nucleation from damage accumulation within slip bands is consistent with observations in Ni-base superalloys at elevated temperatures during LCF tests [25-27], and could be understood in terms of the deformation behavior of superalloys with low stacking fault energy. In TMW4M3, planar slip and deformation localized on slip bands was observed. The resultant strain localization and strain accumulation led to cracking, often on or near the specimen surface in LCF tests.
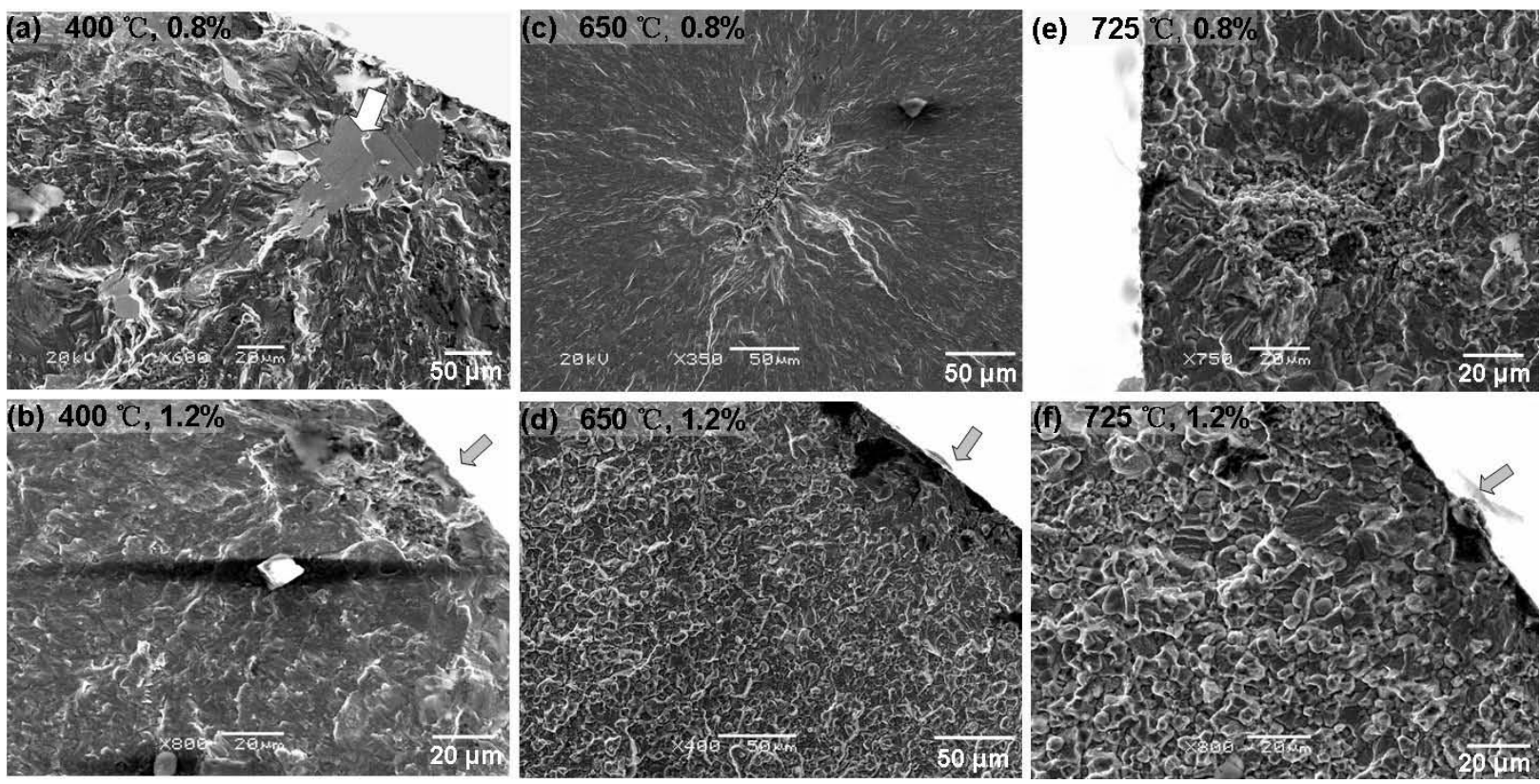

Figure 10. Fractographs of TMW-4M3 showing crack initiation sites: (a) and (b) at $400{ }^{\circ} \mathrm{C}$, (c) and (d) $650{ }^{\circ} \mathrm{C}$, and (e) and (f) at $725^{\circ} \mathrm{C}$. The arrows indicate the crack initiation sites. 

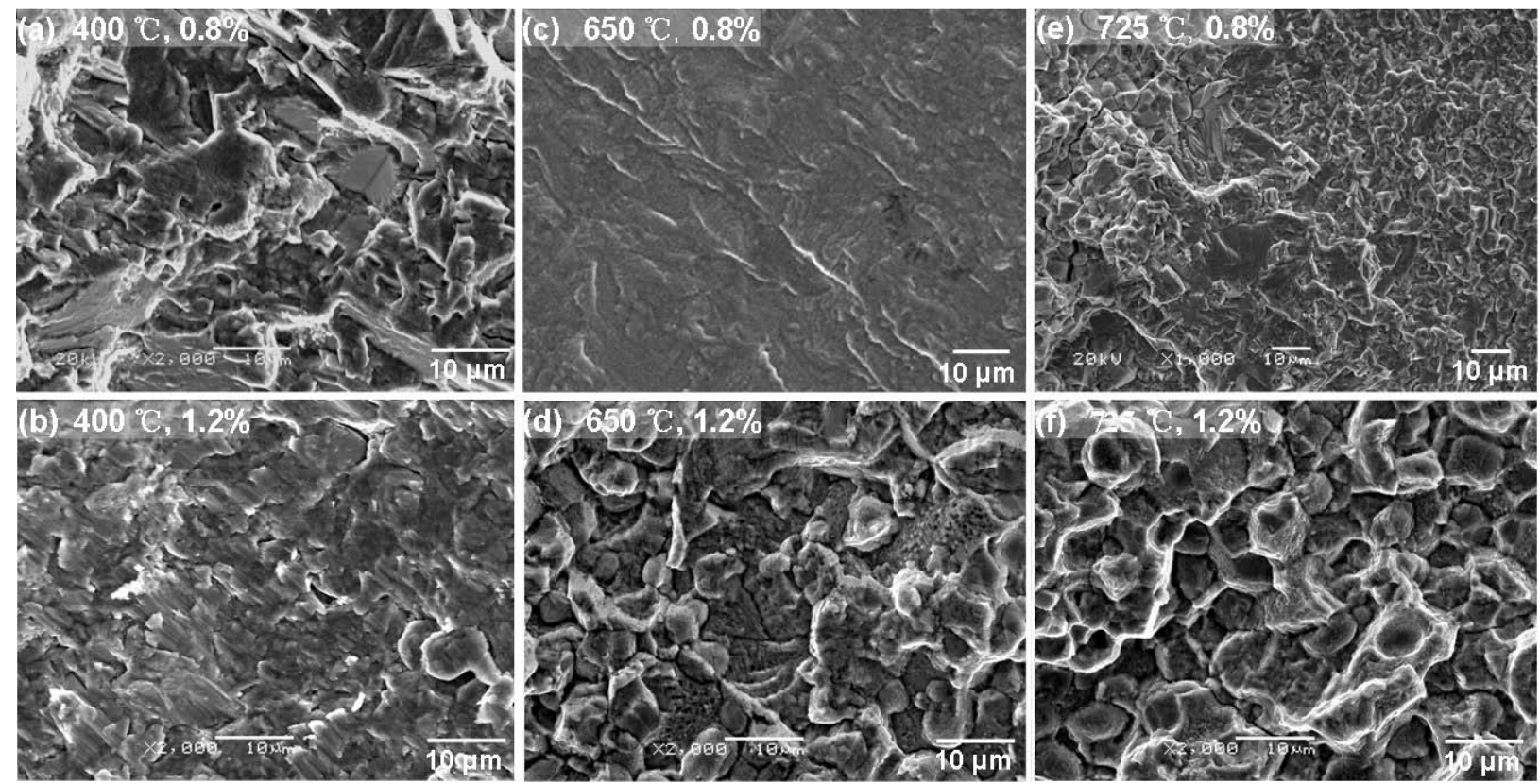

Figure 11. Fractographs of TMW-4M3 showing crack propagation characteristics about $300 \mu \mathrm{m}$ from the crack initiation sites: (a) and (b) at $400{ }^{\circ} \mathrm{C}$, (c) and (d) $650{ }^{\circ} \mathrm{C}$, and (e) and (f) at $725^{\circ} \mathrm{C}$

A feature worthy of consideration in the context of crack initiation is the carbide clusters. These carbides clusters are microstructural inhomogeneities and act as preferred crack initiation sites detrimental to fatigue life. However, the volume of carbides clusters within the specimen is small (Fig.10(c)) and the clusters was found only in the specimen tested at $650{ }^{\circ} \mathrm{C}$ and $\Delta \varepsilon_{\mathrm{t}}=0.8 \%$. Thus, the amount of carbide clusters is very low and the existence of carbide clusters seems to have no significant detrimental effect on the fatigue life (see Fig. 5). One way to eliminate the continuity and minimize the size of carbides in TMW-4M3 is to reduce carbon content. In addition, the higher Ti content in TMW4M3 compared with the conventional C\&W alloys may be partly responsible for the formation of carbide clusters, due to the high chemical affinity of titanium to carbon.

\section{Summary and Conclusions}

The cyclic deformation characteristics and repeated fatigue behavior of a new cast and wrought Ni-Co-base superalloy, TMW-4M3, have been studied at 400,650 and $725{ }^{\circ} \mathrm{C}$ under imposed total strain ranges $\left(\Delta \varepsilon_{t}\right)$ from $0.79 \%$ to $1.22 \%$. Detailed studies were performed on cyclic hardening/softening behavior, deformation substructure, fatigue life, as well as crack initiation and subsequent propagation. The following general conclusions can be drawn from this investigation:

1. Cyclic hardening until the onset of the microcrack initiation occurred under all the imposed strain ranges at $400{ }^{\circ} \mathrm{C}$, whereas immediate softening from the first cycle to failure took place at 650 and $725{ }^{\circ} \mathrm{C}$, except at $650{ }^{\circ} \mathrm{C}$ and $\Delta \varepsilon_{\mathrm{t}}=0.8 \%$ where specimen showed relatively stable stress response until crack initiation.

2. The degree of cyclic hardening or softening increased with increasing the strain range.

3. The inhomogeneous dislocation activity and interaction of dislocations with other dislocations are considered to account for the hardening, while shearing of precipitates by stacking faults and/or coupled dislocation pairs combining with thermal activation process are believed to be responsible for the cyclic softening.

4. The fatigue life showed a single slope behavior in CoffinManson diagrams.

5. Fatigue life decreased with increasing the test temperature or strain range. The reduction in fatigue life with increase in the temperature was not caused by creep effect, but oxidation did accelerate crack propagation at 650 and $725^{\circ} \mathrm{C}$.

6. Crack initiation on or near the surfaces of specimen associated with plastic strain damage accumulation and initiation at subsurface carbide clusters due to its relatively large size compared to $\gamma$ grains, were observed during cycling.

\section{Acknowledgements}

The authors would like to acknowledge the financial support provided by the New Energy and Industrial Technology Development Organization (NEDO), Japan. The Mitsubishi Materials Corporation, Japan, is gratefully acknowledged due to its cooperation with alloy fabrication for the study.

\section{References}

[1] R.C. Reed. The Superalloys:Fundamentals and Applications, Cambridge University Press, Cambridge, 2006.

[2] Y. Gu, H. Harada, C. Cui, D. Ping, A. Sato and J. Fujioka. New Ni-Co-base disk superalloys with higher strength and creep resistance Scripta Mater. 55 (2006) 815-818.

[3] Y.F. Gu, T. Fukuda, C. Cui, H. Harada, A. Mitsuhashi, T. Yokokawa, J. Fujioka,Y. Koizumi, T. Kobayashi. Comparison of mechanical properties of TMW Alloys, new generation of cast-and-wrought superalloys for disk 
applications. Metall Mater Trans A, 40(2009)3047-3050.

[4] H. Harada, Y.F. Gu, C.Y. Cui, M. Osawa, A. Sato, T. Kobayashi. Heat resistant superalloy. European Patent. Patent No. EP 1842934 B1. 2011.

[5] Y. Gu, C. Cui, H. Harada, T. Fukuda, D. Ping, A. Mitsuhashi, K. Kato, T. Kobayashi, and J. Fujioka. In: Superalloy 2008. Edited by R.C. Reed, K.A. Green, P. Caron, T.P. Gabb, M.G. Fahrmann, E.S. Huron, S.R. Woodard. TMS, 2008. 53-61.

[6] H.M. Lu, T. Delph, D.J. Dwyer, M. Gao, R.P. Wei. Environmentally enhanced cavity growth in nickel and nickel-based alloys. Acta Mater. 1996;44(8):3259-66.

[7] K. Gopinath, A.K. Gogia, S.V. Kamat, R. Balamuralikrishnan, U. Ramamurty. Low cycle fatigue behaviour of a low interstitial Ni-base superalloy. Acta Mater., 57(2009)3450-3459.

[8] Y.L. Lu, L.J. Chen, G.Y. Wang, et al. Hold time effects on low cycle fatigue behavior of HAYNES 230® superalloy at high temperatures. Mater. Sci. Eng. A, 409(2005)282-291.

[9] L.F. Coffin. Trans. ASME, 76 (1954), pp 931-950.

[10] S.S. Manson: NACA TN-2933, 1954.

[11] H. Wang, Q.Y. Sun, L. Xiao, J. Sun, P. Ge. Low-cycle fatigue behavior and deformation substructure of Ti-2Al2.5Zr alloy at 298 and 673 K. Mater. Sci. Eng. A, 527(2010) 3493-3500.

[12] B.A. Lerch, N. Jayaraman, S.D. Antolovich. A study of fatigue damage mechanisms in waspaloy from 25 to $800{ }^{\circ} \mathrm{C}$. Mater. Sci. Eng., 66(1984)151-166.

[13] D. Fournier, A. Pineau. Low cycle fatigue behavior of Inconel 718 at $298 \mathrm{~K}$ and $823 \mathrm{~K}$. Metall Trans A. 8 (1977)1095-1105

[14] S.K. Hwang, H.N. Lee, B.H. Yoon. Mechanism of cyclic softening and fracture of an Ni-Base $\gamma$-strengthened alloy under low-cycle fatigue. Metall Mater Trans A, 20(1989)2793-2801.

[15] Y. Yuan, Y.F. Gu, C.Y, Cui, T. Osada, T. Yokokawa, and H. Harada. A novel strategy for the design of advanced engineering alloys-strengthening turbine disk superalloys via twinning structures. Adv. Eng. Mater., 13(2011)296300.

[16] R E Stoltz and A.G Pineau. Dislocation-precipitate interaction and cyclic stress-strain behavior of a $\gamma^{\prime}$ strengthened superalloy. Mater. Sci. Eng., 34(1978)275284.
[17] B.A. Lerch, V. Gerold. Room temperature deformation mechanisms in Nimonic 80A. Acta Metall., 33 (1985) 1709-1716.

[18] H. F. Merrick. The low cycle fatigue of three wrought nickel-base alloys. Metall. Mater. Trans. A 5 (1974)891897.

[19] P.J. Phillips, R.R. Unocic, L. Kovarik, D. Mourer, D. Wei, M.J. Mills. Low cycle fatigue of a Ni-based superalloy:Nonplanar deformation. Scripta Mater., 62(2010)790-793.

[20] M. Valsan, D.H. Shastry, K. Bhanu Sankara Rao, and S.L. Mannan. Effect of strain rate on the high-temperature lowcycle fatigue properties of a Nimonic PE-16 superalloy. Metall. Mater. Trans. A, 25(1994)159-171.

[21] L.J. Chen, Z.G. Wang, G. Yao, J.F. Tian. The influence of temperature on low cycle fatigue behavior of nickel base superalloy GH4049. Int. J. Fatigue, 21(1999)791-797.

[22] K.B.S. Rao, H. Schiffers, H. Schuster, H. Nickel. Influence of time and temperature dependent processes on strain controlled low cycle fatigue behavior of Alloy 617, Metall. Trans. A, 19 (1988)359-371.

[23] K.B.S. Rao, H. Schiffers, H. Schuster, G.R. Halford. Mechanisms of high-temperature fatigue failure in alloy 800H. Metall. Mater. Trans. A, 27 (1996)851-861.

[24] A. Medvedeva, J. Bergström, S. Gunnarsson, J. Andersson. High-temperature properties and microstructural stability of hot-work tool steels. Mater. Sci. Eng. A, 523(2009)39-46.

[25] F. Alexandre, S. Deyber, and A. Pineau. Modelling the optimum grain size on the low cycle fatigue life of a $\mathrm{Ni}$ based superalloy in the presence of two possible crack initiation sites. Scripta Mater., 50(2004)25-30.

[26] A. Boyd-Lee and J.E. King. Short fatigue crack path determinants in polycrystalline Ni-base superalloys. Fatigue Fract. Eng. Mater. Struct., 17(1994)1-14.

[27] J.C. Healy, L. Grabowski and C. J. Beevers. Monitoring fatigue of a nickel-base superalloy at positive and negative stress ratios using an optical system. Fatigue Fract. Eng. Mater. Struct., 15(1992)309-321. 